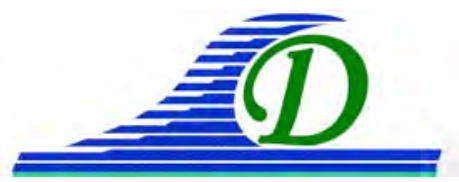

XIII ${ }^{\text {èmes }}$ Journées Nationales Génie Côtier - Génie Civil Dunkerque, 2-4 juillet 2014

DOI:10.5150/jngcgc.2014.044 ～(C) Editions Paralia CFL

disponible en ligne - http://www.paralia.fr - available online

\title{
Dynamique sédimentaire dans la région côtière de Marsa Dhouiba (Nord de la Tunisie)
}

\section{Nouha KHIARI ${ }^{1}$, Mouldi BRAHIM ${ }^{2}$, Abdelfattah ATOUI ${ }^{2}$ Chérif SAMMARI $^{2}$}

1. Faculté des sciences de Tunis, Campus Universitaire Tunis -Université de Tunis El Manar Tunisie -Rommana 1068, Tunis, BP nº 94, Tunisie.

khiarinouha@hotmail.com

2. Institut National des Sciences et Technologies de la Mer- Salammbô-Tunis28, rue de 2 mars 1934, 2025 Salammbô, Tunisie.

mouldi.brahim@instm.rnrt.tn

\section{Communication non présentée}

\section{Résumé :}

Les analyses granulométriques des petits fonds dans la région côtière de Marsa Dhouiba montrent que les courbes cumulatives des sables sont en forme de S. Les sables sont transportés dans un milieu plus au moins agité avec évacuation des particules vers le large par les courants de retour près du fond. Au niveau des profondeurs importantes (entre 10 et $30 \mathrm{~m}$ ), le fond est tapissé par des sables grossiers et graviers. On note l'existence d'un transit sédimentaire le long de la côte; de l'Ouest vers l'Est et un courant de retour côte -large. Ces deux courants sont nés sous l'effet du vent et surtout de la houle de direction Ouest/Nord-Ouest et qui transportent les sédiments les plus fins vers le large. L'évolution des sédiments dans les petites profondeurs est tributaire des apports détritiques par les oueds et les vents. La dynamique sédimentaire dans la région de Marsa Dhouiba est étroitement liée à la houle de direction Ouest Nord/Ouest.

Mots-clés : Sédiments, Dynamique sédimentaire, Nord de la Tunisie, Courant, Houle. 
Thème 2 - Dynamique sédimentaire 
XIII ${ }^{\text {èmes }}$ Journées Nationales Génie Côtier - Génie Civil Dunkerque, 2-4 juillet 2014 
Thème 2 - Dynamique sédimentaire 
XIII ${ }^{\text {èmes }}$ Journées Nationales Génie Côtier - Génie Civil Dunkerque, 2-4 juillet 2014 
Thème 2 - Dynamique sédimentaire 
XIII ${ }^{\text {èmes }}$ Journées Nationales Génie Côtier - Génie Civil Dunkerque, 2-4 juillet 2014 
Thème 2 - Dynamique sédimentaire 